\title{
Probabilistic Modelling for Estimating Gas Kinetics and Decompression Sickness Risk in Pigs During $\mathbf{H}_{2}$ Biochemical Decompression
}

\author{
ANDREAS FAHLMAN* AND SUSAN R. KAYAR ${ }^{\dagger}$ \\ Environmental Physiology Department, \\ Naval Medical Research Center, \\ 503 Robert Grant Avenue, \\ Silver Spring, \\ MD 20910-7500, \\ U.S.A. \\ E-mail: a.fahlman@bham.ac.uk
}

\begin{abstract}
We modelled the kinetics of $\mathrm{H}_{2}$ flux during gas uptake and elimination in conscious pigs exposed to hyperbaric $\mathrm{H}_{2}$. The model used a physiological description of gas flux fitted to the observed decompression sickness (DCS) incidence in two groups of pigs: untreated controls, and animals that had received intestinal injections of $\mathrm{H}_{2}$-metabolizing microbes that biochemically eliminated some of the $\mathrm{H}_{2}$ stored in the pigs' tissues. To analyse $\mathrm{H}_{2}$ flux during gas uptake, animals were compressed in a dry chamber to $24 \mathrm{~atm}\left(\mathrm{ca} 88 \% \mathrm{H}_{2}, 9 \% \mathrm{He}, 2 \% \mathrm{O}_{2}, 1 \% \mathrm{~N}_{2}\right.$ ) for $30-1440 \mathrm{~min}$ and decompressed at 0.9 atm $\min ^{-1}(n=70)$. To analyse $\mathrm{H}_{2}$ flux during gas elimination, animals were compressed to 24 atm for $3 \mathrm{~h}$ and decompressed at $0.45-1.8 \mathrm{~atm} \min ^{-1}(n=58)$. Animals were closely monitored for $1 \mathrm{~h}$ postdecompression for signs of DCS. Probabilistic modelling was used to estimate that the exponential time constant during $\mathrm{H}_{2}$ uptake $\left(\tau_{\text {in }}\right)$ and $\mathrm{H}_{2}$ elimination $\left(\tau_{\text {out }}\right)$ were $79 \pm 25 \mathrm{~min}$ and $0.76 \pm 0.14 \mathrm{~min}$, respectively. Thus, the gas kinetics affecting DCS risk appeared to be substantially faster for elimination than uptake, which is contrary to customary assumptions of gas uptake and elimination kinetic symmetry. We discuss the possible reasons for this asymmetry, and why absolute values of $\mathrm{H}_{2}$ kinetics cannot be obtained with this approach.
\end{abstract}

Published by Elsevier Science Ltd on behalf of Society for Mathematical Biology.

\section{INTRODUCTION}

The risk of decompression sickness (DCS) is believed to be a function of the volumes of gases dissolved in tissues and the rate and magnitude of decompression from a higher pressure (Boycott et al., 1908; Hills, 1978). For humans performing

\footnotetext{
${ }^{*}$ Corresponding address: School of Biosciences, University of Birmingham, Birmingham B15 2TT, U.K.

${ }^{\dagger}$ Current address: National Center for Research Resources, National Institutes of Health, 6701 Democracy Boulevard, Room 924, Bethesda, MD 20892-4874, U.S.A.

E-mail: KayarS@mail.nih.gov.
}

0092-8240/03/040747 + $20 \quad \$ 30.00 / 0 \quad$ Published by Elsevier Science Ltd on behalf of Society for Mathematical Biology. 
deep dives to $15-60$ atm (1.5-6 MPa), $\mathrm{H}_{2}$ is a suitable diluent to $\mathrm{O}_{2}$ in the breathing mixture due to its low density and its special properties that act to reduce symptoms of High Pressure Neurological Syndrome (Abraini et al., 1994). In animal models of $\mathrm{H}_{2}$ diving, the DCS incidence has been successfully reduced in rats (Kayar et al., 1998) and pigs (Fahlman et al., 2001; Kayar et al., 2001) by a process that has been termed $\mathrm{H}_{2}$ biochemical decompression. In this process, $\mathrm{H}_{2}$-metabolizing microbes, Methanobrevibacter smithii (Miller, 1989), are surgically injected into the large intestines of the animals. The microbes metabolize a small but critical fraction of the $\mathrm{H}_{2}$ dissolved in the tissues of these animals during a hyperbaric $\mathrm{H}_{2}$ exposure. The volume of dissolved gas eliminated by this process was previously estimated to be on the order of $12 \%$ of the total gas burden acquired during a $3 \mathrm{~h}$ dive in the pig, or approximately $10 \mathrm{mmol}$, resulting in a decrease in the DCS incidence by as much as 50\% (Kayar et al., 1998; Fahlman, 2001; Fahlman et al., 2001).

Gas fluxes in tissues have been described commonly in hyperbaric research by a time constant, $\tau$ (Tikuisis et al., 1991; Weathersby et al., 1992). The classic models computed the probability of decompression sickness [P(DCS)] as a single exponential time function, which therefore assumes that gas fluxes can be described adequately by one value for $\tau$ for the entire body, with symmetrical kinetics for gas uptake and elimination (Boycott et al., 1908; Weathersby et al., 1984). Recent models have been more successful at predicting DCS outcomes by computing two or more estimates of $\tau$. These have included estimating $\tau$ for compression separately from decompression (Lillo et al., 1997; Lillo and Parker, 2000); estimating separate values of $\tau$ for two different gases in a breathing mixture (Parker et al., 1998); and hypothesizing two or more compartments within dive subjects, with each compartment distinguished by its own $\tau$ (Tikuisis et al., 1991; Himm et al., 1994).

In the study by Fahlman et al. (2001), the gas kinetics of $\mathrm{H}_{2}$ were initially modelled using the data from 109 well-documented hyperbaric exposures of varying durations, pressures, and compression and decompression rates. Initially, the model was designed to estimate two separate time constants for uptake and elimination. However, the separation of different $\tau$ values for uptake and elimination was not validated by the model (Fahlman et al., 2001). Therefore, Fahlman et al., (2001) used one exponential time constant to describe the kinetics, which satisfactorily explained the observed DCS incidence. However, since other DCS modelling efforts (Tikuisis et al., 1991; Himm et al., 1994; Lillo et al., 1997; Parker et al., 1998; Lillo and Parker, 2000) and studies using direct physiological or physical measurements of gas fluxes in animals (D'aoust et al., 1976; Novotny et al., 1990) suggest that the uptake and elimination of gases are asymmetrical, we wanted to perform a critical evaluation of our previous model (Fahlman et al., 2001) in an attempt to gain further understanding of gas fluxes in hyperbaria. Studying gas kinetics and DCS risk in this data set is particularly interesting because of the combination of gas fluxes occurring during conventional decompression and fluxes due to active metabolism of gas during biochemical decompression. 
It must be emphasized that the gas kinetics reported in this and our earlier study (Fahlman et al., 2001) were estimated from changes in DCS incidence rather than from direct measurements of gas fluxes. The computed value for $\tau$ is dependent on observed DCS incidence, the number and types of hyperbaric exposures analysed, and the formulation of the other elements of the mathematical model. It is useful to compute $\tau$ as a mathematical entity in DCS studies because it helps define the general time course of events that we believe correlate with physical or physiological processes. Of particular importance to the present study, we consider whether the time to a given percent completion of the rate function that we define mathematically corresponds to the same level of physical saturation of the dive subject with gas (Lillo and Parker, 2000).

Thus, we have followed the procedures established by others (Lillo et al., 1997; Lillo and Parker, 2000) and separated hyperbaric exposures taken from the study of Fahlman et al. (2001). Of the original 109 exposures, only the 89 exposures that were all at one pressure were retained for this analysis. The exposures that would affect DCS risk due to gas uptake kinetics were for variable time at a single pressure but constant decompression rate; those that would affect DCS risk due to gas elimination kinetics were for a constant time at a single pressure, but variable decompression rates.

\section{METHODS}

Animals and training. All animals were juvenile male Yorkshire pigs (Sus scrofa; $n=89,19.7 \mathrm{~kg} \pm 0.1$ mean body mass $\pm 1 \mathrm{SEM}, 17-23 \mathrm{~kg}$ range). The pigs were housed before experiments in an accredited animal care facility and had ad libitum access to water. They were fed once daily with laboratory animal chow (Harlan Teklad, Madison, WI; $2 \%$ by body weight). All procedures were approved by our institutional Animal Care and Use Committee, and reported as prescribed by national regulations. The experiments reported here were conducted according to the principles presented in the Guide for the Care and Use of Laboratory Animals (U.S. National Research Council, 1996).

Animals were trained to walk at a moderate pace (50-60 $\mathrm{m} \mathrm{min}^{-1}$ ) for intervals of $5 \mathrm{~min}$ on a treadmill in the laboratory, separated by intervals of $5 \mathrm{~min}$ rest, to acclimate them to a treadmill and to verify that this workload was not excessively strenuous. They were then trained to walk at a slower pace $\left(30 \mathrm{~m} \mathrm{~min}^{-1}\right)$ for intervals of $5 \mathrm{~min}$ inside the compression chamber in $1 \mathrm{~atm}$ air, on a treadmill that constituted the floor of the chamber. The pigs were acclimated to being left confined and unattended in the chamber, where they were free to lie down. They were trained to rise and walk whenever the treadmill was activated. Treadmill performance was subsequently used to help evaluate an animal's gait and balance for signs of DCS. 
Microbes and surgery. M. smithii is a species of methanogenic microbes that is native to the intestinal flora of humans and many other mammalian species, including pigs (Miller, 1991). These microbes metabolize $\mathrm{H}_{2}$ as:

$$
4 \mathrm{H}_{2}+\mathrm{CO}_{2} \rightarrow \mathrm{CH}_{4}+2 \mathrm{H}_{2} \mathrm{O} \text {. }
$$

The microbes convert $\mathrm{H}_{2}$ to water and to a readily traceable end product (methane; $\mathrm{CH}_{4}$ ) that is derived almost exclusively from this reaction (Miller, 1991; Kayar et al., 1994). A sample culture of M. smithii (strain PS) was obtained from Dr Terry Miller (Wadsworth Center for Laboratories and Research, Albany, NY, U.S.A.) and was grown in an atmosphere of $\mathrm{H}_{2}: \mathrm{CO}_{2}(80: 20 \mathrm{v} / \mathrm{v} ; 3 \mathrm{~atm})$ at $37^{\circ} \mathrm{C}$ by Dr William Whitman and Mr Winston Lin (Department of Bacteriology, University of Georgia, U.S.A.). Details of the culturing of the microbes appear elsewhere (Kayar et al., 2001). The cultures were stored at $0{ }^{\circ} \mathrm{C}$ and shipped with gel refrigerant to the Naval Medical Research Center within 12-24 h of harvesting. On arrival, the cell suspension bottles were flushed again with $\mathrm{H}_{2} / \mathrm{CO}_{2}$ and stored in a refrigerator for use within the next $24-48 \mathrm{~h}$. Prior to use, the cultures were assayed in vitro for their methanogenic activity by gas chromatography (Kayar et al., 2001).

Animals were divided randomly into three groups (Table 1): those to undergo surgery to be treated with $M$. smithii $(T ; n=29)$, those to undergo the same surgical procedure but given intestinal injections of saline (surgical controls; $n=10$ ), and untreated animals (controls; $n=50$ ). There were no significant differences in body mass between control and treated animal groups $(P>0.15$, ANOVA).

Treated and surgical control animals were prepared for surgery by preanaesthetizing them with injections of ketamine $\mathrm{HCl}\left(20 \mathrm{mg} \mathrm{kg}^{-1}\right.$, i.m.; Fort Dodge Laboratories, Inc., Fort Dodge, IA, U.S.A.) and xylazine (Rompun ${ }^{\circledR} 2 \mathrm{mg} \mathrm{kg}^{-1}$, i.m.; Bayer Corp., Shawnee Mission, KS, U.S.A.). Animals were then kept at a surgical plane of anaesthesia with inhaled isoflurane (Abbott Laboratories, Chicago, IL, U.S.A.) and $\mathrm{O}_{2}$. Using aseptic techniques, a midline incision of approximately $10 \mathrm{~cm}$ was made in the abdomen, and the caecum and spiral colon were exteriorized. For the treated animals, 1-4 injections of $M$. smithii culture were made, depending on the volume of the microbial culture to be used; this volume ranged from 12 to $116 \mathrm{ml}$. Injected microbial activity ranged from 0.20 to $2.20 \mathrm{mmol}$ $\mathrm{CH}_{4} \mathrm{~min}^{-1}$. The injectate was distributed between the caecum, upper, middle and lower spiral colon, with not more than $30 \mathrm{ml}$ in each injection site. All needle puncture sites were sealed with a drop of surgical cement (Vetbond, 3M, St. Paul, MN, U.S.A.). Post-experiment necropsy never revealed any visible leakage from these punctures. The intestines were moistened externally with saline and returned to the abdomen, and the incision was closed with sutures. As the animal recovered from the anaesthesia, yohimbine ( $2 \mathrm{mg}$, i.v.; Lloyd Laboratories, Shenandoah, IA, U.S.A.) was injected into an ear vein, to act as an antagonist to the xylazine. 
Table 1. Summary of hyperbaric exposures of pigs used to estimate time constants for $\mathrm{H}_{2}$ uptake and elimination. Group type, number of animals in each group $(n)$, time held at a pressure of $24 \mathrm{~atm}$ in hyperbaric $\mathrm{H}_{2}$ (Time), decompression rate from 24 to $11 \mathrm{~atm}$ (DR), mean activity ( $\pm 1 \mathrm{SD}$ ) of $\mathrm{H}_{2}$-metabolizing microbes injected into the intestines of the animals (INJ), and number of DCS cases (Outcome) in each group. The group types are control animals $(C)$, animals treated with $\mathrm{H}_{2}$-metabolizing microbes $(T)$, and one treated animal compressed using $\mathrm{He}(T-\mathrm{He})$. (Note that the $C$ group with $n=20$, the $T$ group with $n=18$, and the $T$-He animal appear twice in this table.)

\begin{tabular}{|c|c|c|c|c|c|}
\hline Group & $n$ & $\begin{array}{l}\text { Time } \\
\text { (min) }\end{array}$ & $\begin{array}{c}\mathrm{DR} \\
\left(\mathrm{atm} \min ^{-1}\right)\end{array}$ & $\begin{array}{c}\mathrm{INJ} \\
\left(\mathrm{mmol} \mathrm{CH} \mathrm{min}^{-1}\right)\end{array}$ & $\begin{array}{c}\text { Outcome } \\
\text { (number of cases DCS) }\end{array}$ \\
\hline \multicolumn{6}{|l|}{$\mathrm{H}_{2}$ uptake } \\
\hline C & 9 & 30 & 0.9 & 0 & 2 \\
\hline$C$ & 5 & 120 & 0.9 & 0 & 4 \\
\hline$C$ & 8 & 150 & 0.9 & 0 & 3 \\
\hline$C$ & 20 & 180 & 0.9 & 0 & 16 \\
\hline$C$ & 1 & 1100 & 0.9 & 0 & 1 \\
\hline$T$ & 5 & 150 & 0.9 & $0.91 \pm 0.41$ & 2 \\
\hline$T$ & 18 & 180 & 0.9 & $0.98 \pm 0.53$ & 7 \\
\hline$T$ & 3 & $>1100$ & 0.9 & $0.78 \pm 0.47$ & 1 \\
\hline$T-\mathrm{He}$ & 1 & 180 & 0.9 & 0.24 & 0 \\
\hline \multicolumn{6}{|c|}{$\mathrm{H}_{2}$ elimination } \\
\hline$C$ & 9 & 180 & 0.45 & 0 & 3 \\
\hline$C$ & 20 & 180 & 0.9 & 0 & 16 \\
\hline$C$ & 8 & 180 & 1.8 & 0 & 8 \\
\hline$T$ & 18 & 180 & 0.9 & $0.98 \pm 0.53$ & 7 \\
\hline$T$ & 2 & 180 & 1.8 & $0.89 \pm 0.49$ & 2 \\
\hline$T-\mathrm{He}$ & 1 & 180 & 0.9 & 0.24 & 0 \\
\hline
\end{tabular}

For the surgical controls, the procedure was identical except that saline that had been deoxygenated by bubbling it with $\mathrm{CO}_{2}$ was used as the injectate. One to three injections of saline were made, of $60 \mathrm{ml}$ total volume, also distributed between the caecum and various locations in the spiral colon. Previous analysis (Fahlman et al., 2001) indicated that DCS outcome was not different between untreated controls and surgical controls. This suggested that the anaesthetic agents and the surgical procedure per se were not significantly affecting DCS outcome. Thus these two control groups were pooled in this analysis $(C ; n=60)$.

Post-surgery time needed to be kept as short as possible to avoid the possibility of treated animals losing the intestinal injectates by defecation. Animals appeared to be fully recovered from the anaesthesia in 1-2 $\mathrm{h}$. They were then placed in the compression chamber to commence the experiment. Food and water were freely available in the chamber.

Hyperbaric exposures. The experiments included a variety of different pressurization and depressurization sequences (Table 1). The hyperbaric exposures were 
performed in a dry chamber (WSF Industries, Buffalo, NY, U.S.A.) of 56001 volume at $1 \mathrm{~atm}$. Each animal was subjected to only one hyperbaric exposure.

A hyperbaric $\mathrm{H}_{2}$ exposure commenced with a pressurization of the chamber with $\mathrm{He}$ to $11 \mathrm{~atm}$, and then a flush of the chamber with $\mathrm{H}_{2}$ until the $\mathrm{H}_{2}$ concentration was more than $60 \%$. The pressurization rate was selected such that it allowed the animal to equalize the pressure in its ears (ca $0.15 \mathrm{~atm} \mathrm{~min}^{-1}$ for the first 2-3 atm, up to $0.45 \mathrm{~atm} \mathrm{~min}^{-1}$ at greater pressures). The initial pressurization with $\mathrm{He}$ was necessary as a safety measure to prevent an explosive mixture of $\mathrm{H}_{2}$ and $\mathrm{O}_{2}$ in the chamber, as described elsewhere (Eichert and Fischer, 1986; Kayar et al., 2001). Pressurization then continued with $\mathrm{H}_{2}$, with addition of $\mathrm{O}_{2}$ as needed to maintain normoxia to mild hyperoxia $\left(0.2-0.4 \mathrm{~atm} \mathrm{O}_{2}\right)$. Maximum pressure of these exposures was 24 atm (absolute pressure; $2.4 \mathrm{MPa} ; 759$ feet of seawater pressure equivalent) for lengths of time that varied from $30 \mathrm{~min}$ to $24 \mathrm{~h}$ (Table 1). A gas chromatograph (GC; Hewlett-Packard 5890A, Series II, Wilmington, DE, U.S.A.) measured the concentrations of $\mathrm{O}_{2}, \mathrm{H}_{2}, \mathrm{He}, \mathrm{N}_{2}$, and $\mathrm{CH}_{4}$ in the chamber every $12 \mathrm{~min}$. Final gas composition in the chamber at maximal pressure was roughly $88 \% \mathrm{H}_{2}, 9 \% \mathrm{He}, 2 \% \mathrm{O}_{2}$ and $1 \% \mathrm{~N}_{2}$ for exposures lasting $3 \mathrm{~h}$, with more $\mathrm{H}_{2}$ and less $\mathrm{He}$ and $\mathrm{N}_{2}$ present in the chamber over time. Calibration procedures for flow meters and the GC appear elsewhere (Kayar et al., 2001).

A single treated animal was compressed to 24 atm as described above, except that He was used throughout the exposure (Table 1). This animal acted as a control for microbial activity in the absence of hyperbaric $\mathrm{H}_{2}$.

Thirty minutes prior to depressurization of the chamber, a treadmill on which the animal had been resting was activated and the animal walked for $5 \mathrm{~min}$. This allowed observers to note the posture and gait of each animal at a time point that was not affected by decompression events.

The chamber was depressurized at a selected rate between 0.45 and 1.8 atm $\min ^{-1}$ from 24 to $11 \mathrm{~atm}$, thus making durations of depressurization ranging from 7 to $29 \mathrm{~min}$ (Table 1). Animals were monitored closely during depressurization and while at $11 \mathrm{~atm}$, where they had alternating $5 \mathrm{~min}$ intervals of walk and rest, to watch for signs of DCS. Observations continued either until the animal was declared to manifest signs of DCS, or until $1 \mathrm{~h}$ had passed. Previous experience with a pig model has indicated that $99 \%$ of all manifestations of severe DCS would be evident within $1 \mathrm{~h}$ of the decompression (Dromsky et al., 2000). Animals were then quickly euthanased by flushing the chamber with inert gas (either $\mathrm{He}$ or $\mathrm{H}_{2}$ ) before depressurizing the chamber to $1 \mathrm{~atm}$.

In these hyperbaric exposures, most symptoms were of severe neurological DCS, including limb weakness, paralysis, and seizures (all non-painful but potentially stressful events). Occasionally, signs of pulmonary DCS (laboured breathing) were also observed in addition to the neurological symptoms. Mild manifestations such as skin discoloration and irritability were noted but not considered sufficient to rank as DCS in this study. Every diagnosis of DCS was determined by a consensus of at least three observers who discussed their diagnosis as the events occurred. 
The observers were not blind to the treatments or dive profiles, resulting in the possibility of biased diagnosis. However, the rigorous compression and decompression sequences used throughout this study caused signs of DCS that were in most cases severe enough to leave no ambiguity. In the rare event that the observers did not agree, a detailed description or a viewing of a video recording of the animal were given to a neurologist or diving medical officer to evaluate and pass final judgment.

DCS risk assessment. The probabilistic models used previously were constructed to be well behaved in the sense that the $[\mathrm{P}(\mathrm{DCS})]$ was predicted to be 0 when no pressure reduction occurred and increased with increasing pressure reduction (Weathersby et al., 1992).

The probability of having DCS symptoms at a time $t$, after a decompression step during or after a hyperbaric exposure, is defined as:

$$
\mathrm{P}(\mathrm{DCS})=1.0-\exp \left(-\int_{0}^{T} r d t\right)
$$

while freedom of symptoms until time $t$ is defined as

$$
\mathrm{P}(\text { no DCS })=1.0-\mathrm{P}(\mathrm{DCS})=\exp \left(-\int_{0}^{T} r d t\right)
$$

where $r$ is the risk function (Weathersby et al., 1984). The risk depends on the theory used to describe the mechanism of DCS, and can be one of several measures integrated over the dive and post-dive period.

The $\mathrm{P}(\mathrm{DCS})$ for a particular hyperbaric exposure is defined as the integrated risk throughout the entire hyperbaric exposure until the end of the observation period at $11 \mathrm{~atm}\left(T_{\text {end }}\right)$. Thus, various descriptions of $r$ can result in the same integrated risk for a given dive.

Definition of $\boldsymbol{r}$. For the present analysis, $r$ was described from a single tissue, using the speculation that the maximum $r$ develops immediately after a decompression step (Fahlman et al., 2001). This modelling approach is referred to as Immediate (Imm); the two models analysed in this study are nested variations of this model (Weathersby et al., 1984).

Model. The instantaneous risk $(r)$ is defined as the normalized difference between the net tissue tension $\left(P_{\mathrm{tis}}\right.$, atm) and the absolute ambient pressure $\left(P_{\mathrm{amb}}\right.$, atm) as described earlier (Weathersby et al., 1985, 1992; Thalmann et al., 1997).

$$
r=G \cdot\left(P_{\mathrm{tis}}-P_{\mathrm{amb}}\right) / P_{\mathrm{amb}}
$$

where $P_{\text {tis }}$ is the sum of the tissue tensions of $\mathrm{H}_{2}\left(P_{\text {tis }} \mathrm{H}_{2}\right.$, atm $)$ and $\mathrm{He}\left(P_{\text {tis }} \mathrm{He}\right.$, atm), and $G$ is a scale factor $\left(\mathrm{min}^{-1}\right)$ to be determined from the fitting procedure. In this model, $r$ is constrained to be 0 or any positive number, and accordingly, 
$r$ will be set to zero at any time $P_{\mathrm{amb}}>P_{\text {tis }}$ (Weathersby et al., 1985, 1992; Fahlman et al., 2001).

Tissue partial pressures $\left(\boldsymbol{P}_{\text {tis }}\right)$. We used an exponential kinetics model to describe the tissue partial pressures of the inert gases, assuming the animal to be a single compartment. Thus, the differential equation used to describe the inert gas tissue partial pressure was as follows:

$$
\frac{d P_{\mathrm{tis}}}{d t}=\frac{P_{\mathrm{blood}}}{\tau}-\frac{P_{\mathrm{tis}}}{\tau}
$$

where $P_{\text {tis }}$ is the tissue tension of the inert gas (atm), $P_{\text {blood }}$ is the arterial blood tension of the inert gas (atm), $t$ is time ( $\mathrm{min}$ ), and $\tau$ is the whole animal exponential time constant $(\mathrm{min})$ to be determined from the data. For this as in earlier models (Fahlman et al., 2001), it is assumed that $\tau$ is the same for $\mathrm{He}$ and $\mathrm{H}_{2}$. At normal atmospheric temperatures and pressures, gaseous $\mathrm{H}_{2}$ does not readily dissociate into ions (Farkas, 1935; Kayar et al., 1994); we therefore did not include hydrogen in any other form than $\mathrm{H}_{2}$ in the model.

In this study, the hyperbaric exposures were divided into two groups: those for which changing time events occurred at constant pressure (variable time at $24 \mathrm{~atm}$ ), and those for which changing time events occurred during decompression (variable decompression rate; Table 1). This dichotomy of the data allowed us to compute separate values for $\tau$ for $\mathrm{H}_{2}$ uptake $\left(\tau_{\text {in }}\right)$ and elimination $\left(\tau_{\text {out }}\right)$, respectively (Lillo and Parker, 2000). (Note that three groups of animals appear twice in Table 1 because their hyperbaric exposures were appropriate for the analysis of both $\tau_{\text {in }}$ and $\tau_{\text {out. }}$ )

For this study, the change in $P_{\text {blood }}$ during compression and decompression is assumed to be instantaneous and therefore equal to the alveolar partial pressure $\left(P a_{\text {in }}\right)$ for that inert gas at all times. The $P a_{\text {in }}$ is in turn assumed to be equal to the ambient pressure $\left(P_{\mathrm{amb}}\right)$ for that gas. The correction for water vapour and $\mathrm{CO}_{2}$, using the alveolar gas equation, was shown earlier to be negligible and was therefore omitted (Weathersby et al., 1987; Fahlman et al., 2001). The effect of a change in $P_{\text {blood }}$ on $P_{\text {tis }}$ is computationally straightforward but extensive over a changing compression and decompression sequence, and has been described in detail elsewhere (Weathersby et al., 1985; Thalmann et al., 1997). In short, $P_{\text {tis }}$ was computed using the appropriate equation [e.g., equation (5) in the case of no $\mathrm{H}_{2}$ metabolism] throughout the compression and decompression sequence by dividing each sequence into pressure-time ramps followed by numerical integration.

Thus two parameters needed to be determined for the variable compression time data $\left(\tau_{\text {in }}\right.$ and $\left.G_{\text {in }}\right)$ and for the variable decompression rate data ( $\tau_{\text {out }}$ and $\left.G_{\text {out }}\right)$.

Effect on tissue tension by $\boldsymbol{H}_{2}$ metabolism. Animals injected with $M$. smithii have been shown previously to have a significantly lower incidence of DCS than untreated animals (Fahlman et al., 2001; Kayar et al., 1998, 2001). A hypothesis 
describing how the microbial metabolic conversion of $\mathrm{H}_{2}$ into $\mathrm{CH}_{4}$ in the intestine has a global effect on the $P_{\text {blood }}$ was incorporated into a probabilistic model (Fahlman et al., 2001). Inclusion of the parameter for $\mathrm{H}_{2}$ metabolism significantly improved the prediction of $\mathrm{P}(\mathrm{DCS})$. For the present analysis, the equation including methanogenesis is of the form used by Fahlman et al. (2001):

$$
\frac{d P_{\mathrm{tis}} \mathrm{H}_{2}}{d t}=\frac{P_{\text {blood }} \mathrm{H}_{2}-\mathrm{BUG} \cdot A_{\mathrm{INJ}}}{\tau}-\frac{P_{\mathrm{tis}} \mathrm{H}_{2}}{\tau}
$$

where BUG is the rate of $\mathrm{H}_{2}$ removal as determined by the total microbial activity injected into the intestines (INJ, $\mathrm{mmol} \mathrm{CH}_{4} \mathrm{~min}^{-1}$ ), and $A_{\mathrm{INJ}}$ (atm min $\mathrm{mmol}^{-1} \mathrm{CH}_{4}$ ) is the parameter to be determined. Consequently, including the removal of $\mathrm{H}_{2}$ due to microbial $\mathrm{H}_{2}$ metabolism results in three parameters that need to be determined for each model; $\tau_{\text {in }}, G_{\text {in }}$, and $A_{\text {INJin }}$ for $\mathrm{H}_{2}$ uptake, and $\tau_{\text {out }}$, $G_{\text {out }}$, and $A_{\mathrm{INJ} \text { out }}$ for $\mathrm{H}_{2}$ elimination.

Thus, there were two models to be tested in this study: Imm 2, the two-parameter model solving for parameter fits for $\tau$ and $\mathrm{G}$ from equation (2) (or (3)), (4), and (5); and Imm 3, the three-parameter model solving for parameter fits for $\tau, \mathrm{G}$ and $A_{\text {inj }}$ from equation (2) (or (3)), (4), (5) (for $\mathrm{He}$ ) and (6) (for $\mathrm{H}_{2}$ ). Each of these models was used to analyse $\mathrm{H}_{2}$ uptake and $\mathrm{H}_{2}$ elimination kinetics separately.

The parameters were determined from the data by fitting the estimated P(DCS) to the observed DCS outcome. Consequently, P(DCS) needed to be estimated for each hyperbaric exposure using equation (2) or (3). If the animal did not manifest DCS by the end of the $1 \mathrm{~h}$ observation period at $11 \mathrm{~atm}$, the hyperbaric exposure was considered to be safe from the start of the dive until the end of the observation period $\left(T_{\text {end }}\right)$.

A modified Marquardt nonlinear parameter estimation routine using the method of maximum likelihood was used to search for best fitting parameters (Fahlman, 2001). The likelihood ratio test was used to determine the significance of parameters compared to the Null model (Weathersby et al., 1984). A grid search over all floating parameters, involving over 700 unique starting parameter-value sets, was used to increase the likelihood of finding global rather than local loglikelihood (LL) maxima.

Null model. A special case of the risk function model is a more general and simplified model that ignores the specifics of the dive history and considers the instantaneous risk to be constant at all times during the decompression.

$$
\begin{aligned}
& r=0 \quad \text { before decompression begins } \\
& r=\text { constant } \quad \text { after decompression begins. }
\end{aligned}
$$

The scale factor $G$ is set to one and not considered a parameter. This model is therefore referred to as the constant hazard, or Null model, and will be used to make comparisons with LL values for more complex models. 
Table 2. Parameter estimates ( \pm 1 SEM) and LL values for $\mathrm{H}_{2}$ uptake in pigs compressed to $24 \mathrm{~atm}$ and decompressed at $0.9 \mathrm{~atm} \min ^{-1}(n=70)$. Parameters include: $r_{\mathrm{in}}$, instantaneous risk of DCS; $\tau_{\text {in }}$, time constant for $\mathrm{H}_{2}$ uptake; $G_{\text {in }}$, scale factor; $A_{\text {INJin }}$, factor for the total $\mathrm{H}_{2}$-metabolizing activity injected into the animal. $P$ values indicate level of significant change in LL from the preceding model.

\begin{tabular}{cccccc}
\hline Model & $\begin{array}{c}r_{\text {in }} \\
\left(\mathrm{min}^{-1}\right)\end{array}$ & & LL & P \\
\hline Null & 0.0097 & & -48.59 & \\
\hline & $\begin{array}{c}\tau_{\text {in }} \\
(\min )\end{array}$ & $\begin{array}{c}G_{\text {in }} \\
\left(\mathrm{min}^{-1}\right)\end{array}$ & $\begin{array}{c}A_{\text {INJin }} \\
\left(\text { atm min } \mathrm{mmol}^{-1} \mathrm{CH}_{4}\right)\end{array}$ & & \\
\hline Imm 2 & $72 \pm 29$ & $0.019 \pm 0.003$ & & -46.61 & $<0.05$ \\
Imm 3 & $79 \pm 25$ & $0.025 \pm 0.005$ & $3.73 \pm 0.66$ & -43.02 & $<0.01$ \\
\hline
\end{tabular}

\section{RESULTS}

The DCS incidence in control animals increased with increasing time spent at a constant pressure of $24 \mathrm{~atm}$, from $22 \%$ after $30 \mathrm{~min}$ to $80 \%$ after $180 \mathrm{~min}$ (Table 1). The DCS incidence increased with increasing decompression rate, from $33 \%$ at a decompression rate of $0.45 \mathrm{~atm} \mathrm{~min}^{-1}$ to $100 \%$ at a rate of $1.8 \mathrm{~atm} \mathrm{~min}^{-1}$ (Table 1). Animals receiving the microbial treatments generally had a lower incidence of DCS than their control counterparts; only 39\% of treated animals manifested DCS after 180 min constant pressure and with decompression at a rate of $0.9 \mathrm{~atm} \mathrm{~min}^{-1}$, which was significantly different from $80 \%$ incidence in the corresponding control group (Table $1, P<0.05, \chi^{2}$ test).

The two-parameter model (Imm 2) was a better representation of the data than the Null model, both for the $\mathrm{H}_{2}$ uptake $\left(P<0.05\right.$; Table 2) and the $\mathrm{H}_{2}$ elimination $(P<0.01$; Table 3$)$ data sets. Therefore, incorporating a specific description of the dive history significantly improved the fit to these data.

The three-parameter model (Imm 3) was a better representation of the data than the two-parameter model, both for the $\mathrm{H}_{2}$ uptake $(P<0.01$; Table 2$)$ and the $\mathrm{H}_{2}$ elimination $(P<0.01$; Table 3$)$ data sets. The benefits of adding $\mathrm{A}_{\text {inj }}$ to the model may be illustrated by simple graphics (Figs 1 and 2): one regression curve for control and treated animals together [Figs 1(a) and 2(a)] did not represent the data as well as separate regression curves [Figs 1(b) and 2(b)]. Therefore, including a factor for microbial activity was useful for describing the generally lower P(DCS) in the treated animals.

From the variable time at constant pressure data, the $\tau_{\text {in }}$ was estimated to be $79 \pm 25 \mathrm{~min}$ (Table 2), whereas from the variable decompression rate data, the $\tau_{\text {out }}$ was estimated to be $0.76 \pm 0.14$ min (Table 3 ). The $95 \%$ confidence limits of these parameter estimates did not overlap, suggesting that the $\tau_{\text {in }}$ and $\tau_{\text {out }}$ were significantly different. 
Table 3. Parameter estimates $\left( \pm 1\right.$ SEM) and LL values for $\mathrm{H}_{2}$ elimination in pigs compressed to $24 \mathrm{~atm}$ for $3 \mathrm{~h}$ and decompressed at $0.45,0.90$, and $1.80 \mathrm{~atm} \min ^{-1}$ $(n=58)$. Parameters include: $r_{\text {out }}$, instantaneous risk of DCS; $\tau_{\text {out }}$, time constant for $\mathrm{H}_{2}$ elimination; $G_{\text {out }}$, scale factor; $A_{\text {INJout }}$ factor for the total $\mathrm{H}_{2}$-metabolizing activity injected into the animal. $P$ values indicate level of significant change in LL from the preceding model.

\begin{tabular}{cccccc}
\hline Model & $\begin{array}{c}r_{\text {out }} \\
\left(\mathrm{min}^{-1}\right)\end{array}$ & & LL & P \\
\hline Null & 0.013 & & -39.98 & \\
\hline & $\begin{array}{c}\tau_{\text {out }} \\
(\mathrm{min})\end{array}$ & $\begin{array}{c}G_{\text {out }} \\
\left(\mathrm{min}^{-1}\right)\end{array}$ & $\begin{array}{c}A_{\text {INJout }} \\
\left(\mathrm{atm} \mathrm{min} \mathrm{mmol}^{-1} \mathrm{CH}_{4}\right)\end{array}$ & & \\
\hline Imm 2 & $0.80 \pm 0.18$ & $2.90 \pm 1.20$ & $0.18 \pm 0.06$ & -35.40 & $<0.01$ \\
Imm 3 & $0.76 \pm 0.14$ & $4.10 \pm 1.69$ & -31.34 & $<0.01$ \\
\hline
\end{tabular}

Both $\tau_{\text {in }}$ and $\tau_{\text {out }}$ estimates were negligibly changed by addition of the $\mathrm{A}_{\text {inj }}$ parameter (Tables 2 and 3). This suggests that the effect of the microbial activity was adequately represented by equation (6), and was not affecting the time course of events associated with DCS risk in the treated animals.

\section{DISCUSSION}

A common method for modelling inert gas exchange in whole animals considers the animal as a single, well-stirred tissue with one exponential time constant (Weathersby et al., 1984). This approach was followed in a previous analysis of $\mathrm{H}_{2}$ biochemical decompression in a pig model (Fahlman et al., 2001), from which a single $\tau$ for $\mathrm{H}_{2}$ uptake and elimination of 0.7-2 min was derived, depending on model assumptions. Although experiments have shown that more complex models are required to describe real tissues (Novotny et al., 1990; Himm et al., 1994), the simplicity of a single time constant for estimating the time when tissues reach equilibrium with the ambient pressure is appealing. Years of experience with the maximum likelihood technique have shown that a large number of experiments are necessary to solve problems such as differences in gas potencies for inducing DCS (Lillo, 1988; Lillo and MacCallum, 1991), or asymmetrical exchange kinetics for compression and decompression (Thalmann et al., 1997; Lillo and Parker, 2000). Since large data sets are not always feasible, some studies have limited the physiological models by either restricting the complexity of the model (Fahlman et al., 2001) or restricting the experiments to a small number of compression and decompression sequences (Lillo et al., 1985; Lillo, 1988). The present study likewise separated the experiments into those that featured changes in time spent at constant pressure, and those that featured changes in time spent during decompression. 

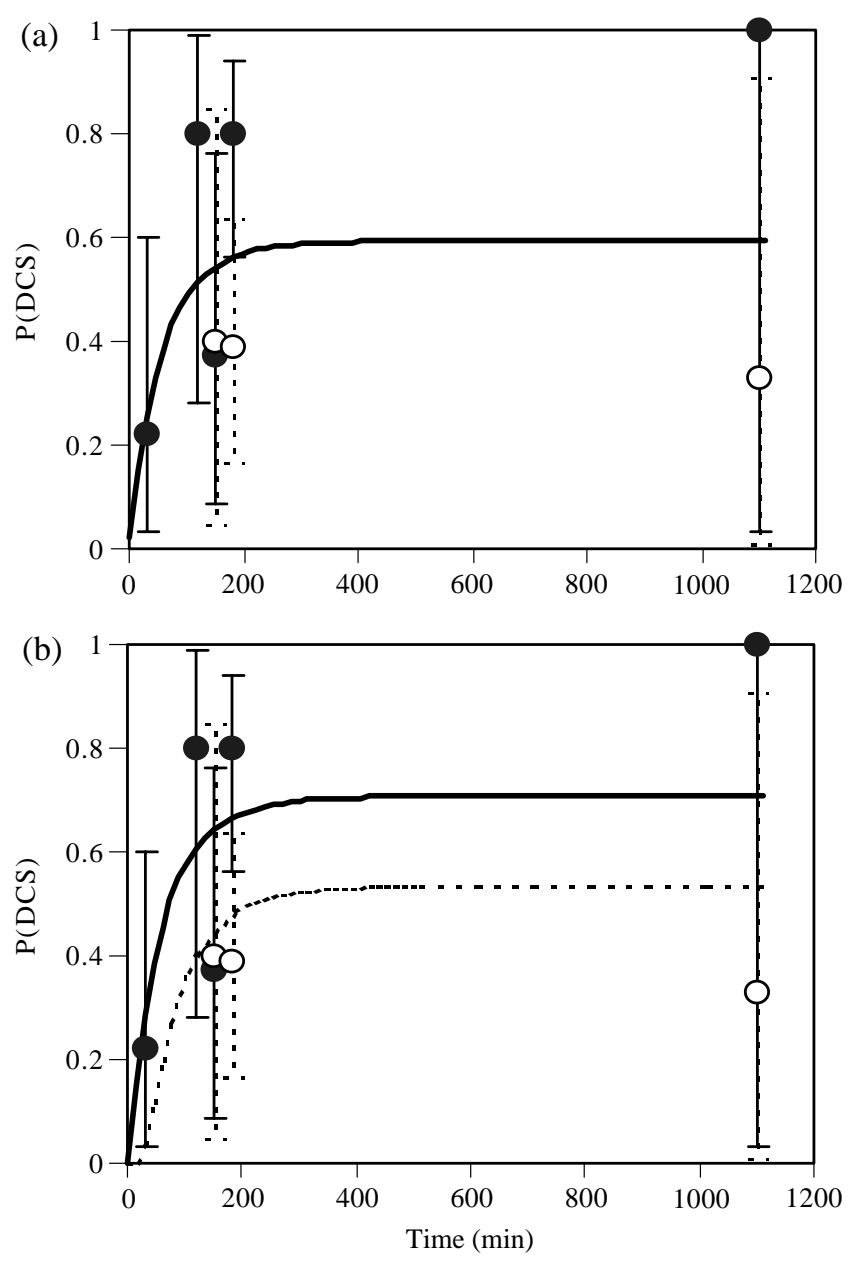

Figure 1. $\mathrm{P}(\mathrm{DCS})$ vs. variable time at a constant pressure of $24 \mathrm{~atm}$ in hyperbaric $\mathrm{H}_{2}$, using a decompression rate of $0.9 \mathrm{~atm} \mathrm{~min}^{-1}$. (a) Curve represents model Imm 2 fit to data from a control animal. (b) Solid curve represents model Imm 3 fit to data from a control animal and the dotted curve represents model Imm 3 fit to data from a treated animal with a standardized treatment of $0.8 \mathrm{mmol} \mathrm{CH}_{4} \mathrm{~min}^{-1}$ activity. Solid circles represent observed DCS incidence for control animals $(n=43)$; open circles represent observed DCS incidence for treated animals $(n=27)$. Error bars represent $95 \%$ confidence limits on binomially-distributed data. (Data from the treated animal in $\mathrm{He}$ are included in the models but are not shown in the observed data points.)

The $\tau$ value of $0.7-2$ min previously estimated from the entire data set (Fahlman et al., 2001) represented a combination of $\mathrm{H}_{2}$ uptake and $\mathrm{H}_{2}$ elimination kinetics. This value is much shorter than the $\tau_{\text {in }}$ value of $79 \mathrm{~min}$ (Table 2), but comparable to the $\tau_{\text {out }}$ value of $0.76 \mathrm{~min}$ (Table 3 ) estimated in the present analysis. Apparently, the $\tau$ estimate of Fahlman et al. (2001) is more a reflection of the time course of events occurring during $\mathrm{H}_{2}$ elimination than during $\mathrm{H}_{2}$ uptake. 

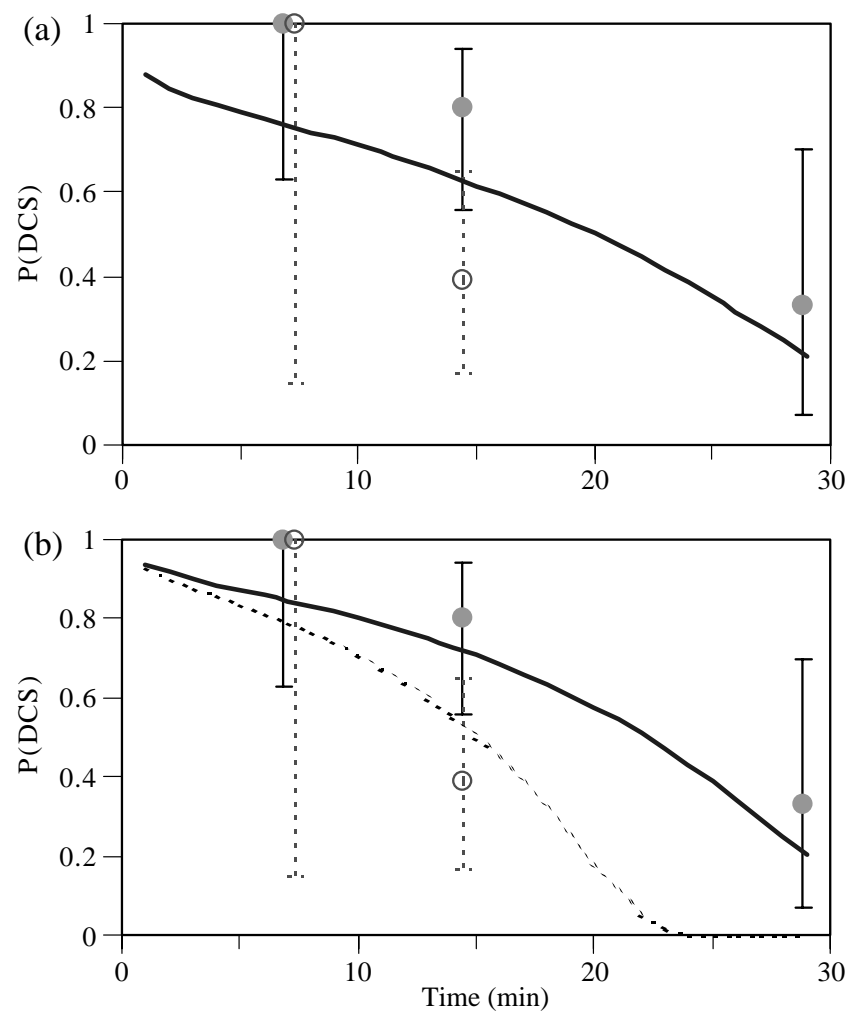

Figure 2. $\mathrm{P}(\mathrm{DCS})$ vs. variable time spent decompressing from 24 to $11 \mathrm{~atm}$ in hyperbaric $\mathrm{H}_{2}$ after $180 \mathrm{~min}$ at $24 \mathrm{~atm}$. (a) Curve represents model Imm 2 fit to data from a control animal. (b) Solid curve represents model Imm 3 fit to data from a control animal and the dotted curve represents model Imm 3 fit to data from a treated animal with a standardized treatment of $0.8 \mathrm{mmol} \mathrm{CH}_{4} \mathrm{~min}^{-1}$ activity. Solid circles represent observed DCS incidence for control animals $(n=37)$; open circles represent observed DCS incidence for treated animals $(n=21)$. Error bars represent $95 \%$ confidence limits on binomially-distributed data. (Data from the treated animal in He are included in the models but are not shown in the observed data points.)

Thus in these experiments, a single value for $\tau$ representing both $\mathrm{H}_{2}$ uptake and elimination kinetics is highly biased.

The data from control animals indicated that a change in P(DCS) from $80 \%$ risk to $20 \%$ risk could be elicited either by changing the length of time spent at constant pressure by a period of 1.5-2.5 h (Fig. 1), or by changing the length of time spent decompressing by a period of 15-20 min (Fig. 2). Similar results were obtained from the Imm 3 risk function analysis. Shortening the time spent at constant pressure from 180 to $30 \mathrm{~min}$ reduced the model's predicted P(DCS) from $66 \%$ [Fig. 3(a)] to 24\% [Fig. 3(b)]. Lengthening the time spent decompressing from $14 \mathrm{~min}$ (by decompressing from 24 to $11 \mathrm{~atm}$ at a rate of $0.9 \mathrm{~atm} \mathrm{~min}^{-1}$ ) to $29 \mathrm{~min}$ (by decompressing from $24 \mathrm{~atm}$ to $11 \mathrm{~atm}$ at a rate of $0.45 \mathrm{~atm} \mathrm{~min}^{-1}$ ) reduced the predicted P(DCS) from $73 \%$ [Fig. 4(a)] to $23 \%$ [Fig. 4(b)]. It is customary in DCS 


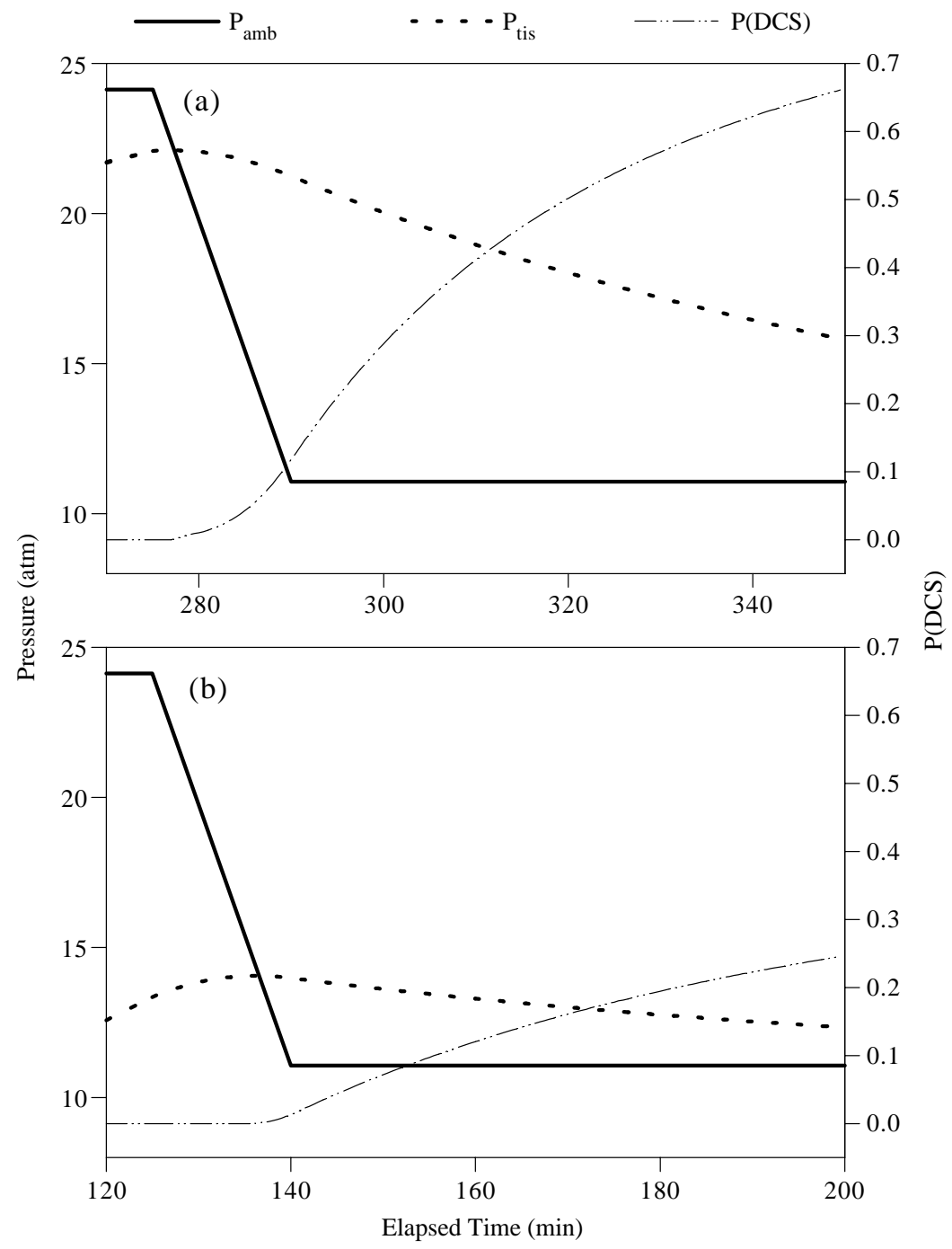

Figure 3. Ambient pressure $\left(P_{\mathrm{amb}}\right)$, inert gas tissue tension $\left(P_{\text {tis }}\right)$, and $\mathrm{P}(\mathrm{DCS})$ vs. time at constant pressure for a control animal after (a) $180 \mathrm{~min}$ or (b) $30 \mathrm{~min}$ in hyperbaric $\mathrm{H}_{2}$, using a constant decompression rate of $0.9 \mathrm{~atm} \mathrm{~min}^{-1}$. Parameters of model Imm 3 for $\mathrm{H}_{2}$ uptake (Table 2) were used to determine the $P_{\text {tis }}$ and P(DCS).

research to assume that $\tau$ is a reflection of the time course of physical events within the dive subject, despite the fact that in our approach it is a purely mathematical construct from a physiological model related to the observed DCS incidence (Lillo and Parker, 2000; Fahlman et al., 2001). Specifically, the time point after which the number of DCS cases no longer increases with increasing time at a given pressure is taken literally as the time needed to attain physical saturation with gas; the 50th percentile point of this risk function is considered half of saturation (Lillo and Parker, 2000). This is intuitively reasonable, at least for $\tau_{\text {in }}$, based on 


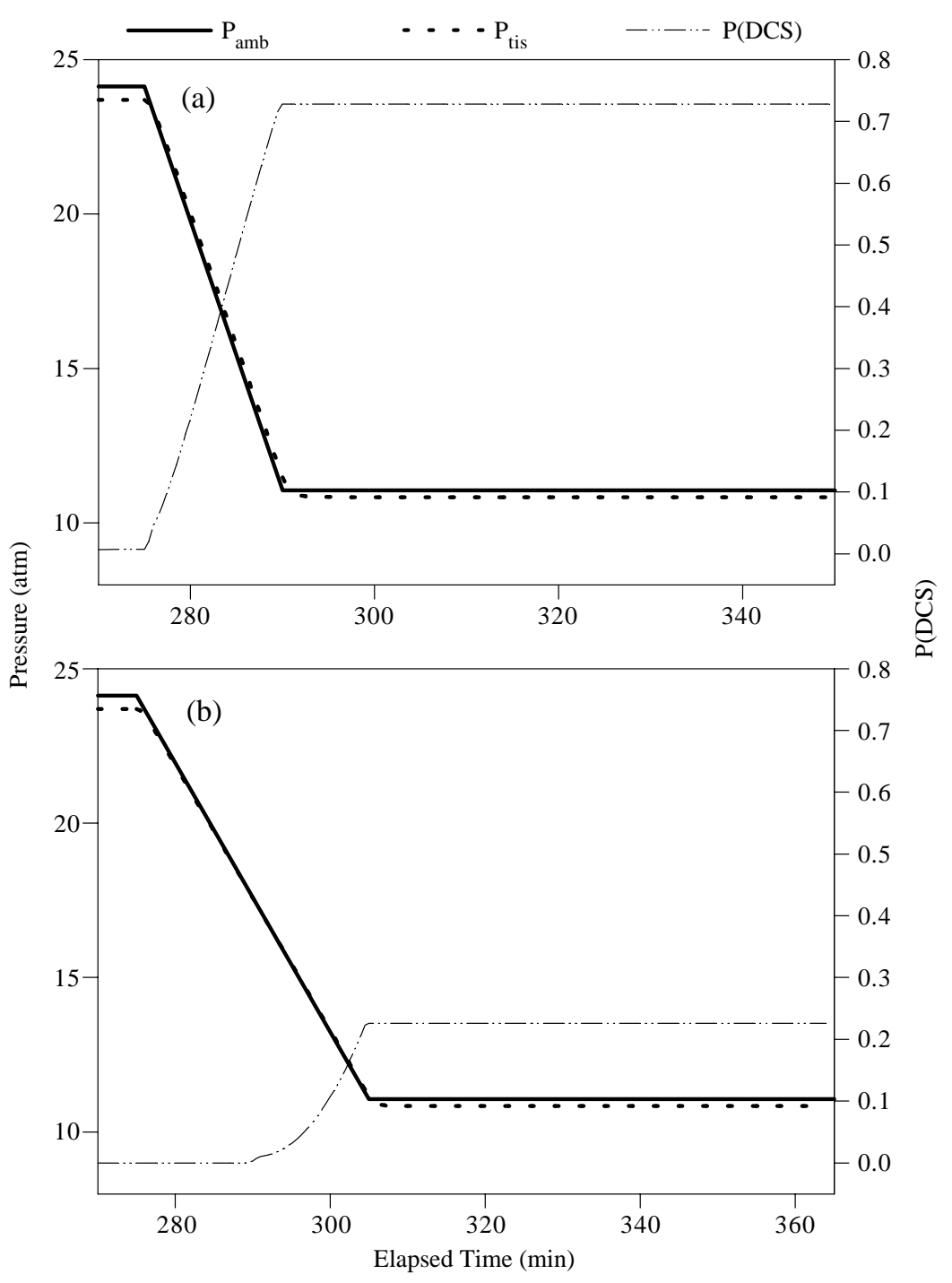

Figure 4. Ambient pressure $\left(P_{\mathrm{amb}}\right)$, inert gas tissue tension $\left(P_{\mathrm{tis}}\right)$, and $\mathrm{P}(\mathrm{DCS})$ vs. time at constant pressure for a control animal after $180 \mathrm{~min}$ in hyperbaric $\mathrm{H}_{2}$, using a decompression rate of (a) $0.9 \mathrm{~atm} \mathrm{~min}^{-1}$ or (b) $0.45 \mathrm{~atm} \mathrm{~min}^{-1}$. Parameters of model Imm 3 for $\mathrm{H}_{2}$ elimination (Table 3 ) were used to determine the $P_{\text {tis }}$ and $\mathrm{P}(\mathrm{DCS})$.

long-standing concepts of DCS risk and gas loading (Boycott et al., 1908). The computed $\tau$ values, by virtue of being exponential time constants, thus can be used to compute time to $50 \%$ completion $\left(\tau_{1 / 2}\right)$ of inert gas uptake as $\tau_{1 / 2}=\ln 2 \cdot \tau$ (Johnson and Kiokemeister, 1996). The time required to reach a certain fractional transformation to the new saturated steady state, say 95 or $99 \%$, can be computed as $3 \cdot \tau$ and $4.6 \cdot \tau$, respectively (Johnson and Kiokemeister, 1996). Thus, the $\tau_{\text {in }}$ value in this study can be interpreted to mean that animals were 50 and $99 \%$ saturated with $\mathrm{H}_{2}$ after 55 and 363 min, respectively (Table 2), regardless of treatment. 
It is less clear how literally the times derived for $\tau_{\text {out }}$ should be taken to reflect time to a given percentage of desaturation. The $\tau_{\text {out }}$ was estimated to be $0.76 \mathrm{~min}$ (Table 3), which would mean that the time to 50 and $99 \%$ completion towards the new decompression steady state would be in 0.5 and $3.5 \mathrm{~min}$, respectively, under the conventional assumption. Direct observations of human divers by Doppler ultrasound imaging have found evidence of $\mathrm{N}_{2}$ bubbles circulating hours after decompressing from air dives, with poor correlation between the quantity or persistence of bubbles and DCS incidence (Nishi, 1993). There is also a growing body of evidence that a significant portion of DCS risk is attributable to an inflammatory response to bubbles or bubble-induced damage, rather than to the gas load itself (Ward et al., 1990; Kayar et al., 1997). Thus, DCS risk may not be tightly coupled to residual post-decompression gas load (Ball et al., 1995). These observations lead us to suspect that the calculated $\tau$ values, particularly $\tau_{\text {out }}$, may not be literal indices of gas saturation. It seems nevertheless reasonable to view them as useful tools for linking times with DCS risk, if not with gas load per se.

In some previous studies, a longer $\tau$ was found for gas elimination than gas uptake (Hills, 1978; Lillo et al., 1997). Similar results were found by direct measurement of $\mathrm{N}_{2}$ washout in dogs (D'aoust et al., 1976); this study also showed that the washout rate of the $\mathrm{N}_{2}$ decreased with increasing residual $\mathrm{N}_{2}$ tension immediately post-decompression (D'aoust et al., 1976). This was interpreted to mean that during decompression, gas that evolves into bubbles becomes subject to much slower kinetics for further elimination, with persistent DCS risk linked to persistent tissue gas presence (Hills, 1978; Lillo et al., 1997). However, Lillo and Parker (2000) estimated $\tau$ values that were much faster for gas elimination than uptake; they proposed that the coupling between DCS risk and post-decompression gas load may be weak and variable, depending on the gas mixture, maximal pressures and decompression rates examined. In a mathematical model of bubble dynamics in DCS, Tikuisis et al. (1991) predicted that the time for a gas in a tissue to reach pressure equilibrium between the dissolved phase and the gas phase within a bubble could be much shorter than the estimated time constant for gas uptake. Thus, we speculate that our short $\tau_{\text {out }}$ predictions may be related to bubble formation kinetics rather than gas washout from the body.

It is clear that the data from the treated animals demonstrate a need for separate mathematical consideration from controls (Figs 1 and 2). Our chosen physiological model included the effects of the microbial treatments for $\mathrm{H}_{2}$ biochemical decompression as a separate parameter, $A_{\text {inj }}$ [equation (6)], which operates to lower $P_{\text {tis }}$. An alternative might have been to compute a separate $\tau$ for control vs. treated animals, but this did not fit our concept of the underlying physiology. Both the analysis by Fahlman et al. (2001) using the complete data set, and the present analysis that separated $\mathrm{H}_{2}$ uptake and elimination events (Tables 2 and 3), successfully incorporated $A_{\text {inj }}$ into significant models with minimal impact on $\tau$ estimates. This suggests that our $\tau$ estimates are reasonably robust, and 
that DCS risk reduction via biochemical decompression can be viewed as a phenomenon of lowering tissue gas load, rather than changing gas uptake or elimination kinetics.

A potentially important point may be made by noting that the risk function curves for control vs. treated animals converge at short times at constant pressure [Fig. 1(b)] and at fast decompression rates [Fig. 2(b)]. We interpret this as indicating that biochemical decompression is successful at significantly reducing DCS risk in these animals if time at constant pressure is at least $3 \mathrm{~h}$, and time spent decompressing is at least $14 \mathrm{~min}$. The gas scrubbing by $\mathrm{H}_{2}$ biochemical decompression may not be adequate to be a demonstrable advantage if the time spent at pressure is very short, or the decompression is very rapid.

\section{CONCLUSION}

We conclude that there is considerable asymmetry in the exponential time constants during $\mathrm{H}_{2}$ uptake vs. $\mathrm{H}_{2}$ elimination in this animal model. The evolution of events contributing to DCS risk appears to be much faster during $\mathrm{H}_{2}$ elimination than uptake. This analysis continues to support the concept of $\mathrm{H}_{2}$ biochemical decompression as a viable means of DCS risk reduction, so long as sufficient time for microbial metabolism is allotted at constant pressure and during decompression. Hydrogen biochemical decompression can be significantly modelled as a process that lowers DCS risk by reducing the total volume of dissolved $\mathrm{H}_{2}$, using gas kinetics that are the same as in conventional decompression.

\section{ACKNOWLEDGements}

Some truly golden days were spent in the company of the Phase III team whose devotion to doing things well was all that made this research possible. We thank Mr Richard Ayres, Mr Jerry Morris, Mr Roland Ramsey and Chief Anthony Ruopoli most of all for their friendship. We gratefully thank Ms Diana Temple for moral support, editorial assistance and critical reading of this manuscript.

This work was funded by the Naval Medical Research and Development Command Work Unit No. 61153N MR04101.00D-1103. The opinions and assertions contained herein are the private ones of the authors and are not to be construed as official or reflecting the views of the Navy Department and the naval service at large.

\section{APPENDIX}

The time constant for gas kinetics in animals is believed to be correlated with the blood perfusion rate (Thalmann et al., 1997). Metabolic rate, heart rate, and blood perfusion rate of animals are all correlated with environmental temperature and body size (Schmidt-Nielsen, 1984). Inclusion of animal mass has been shown 
previously to improve the model fit for DCS risk in rats (Lillo and Parker, 2000). Ambient temperature may also play a role in DCS risk, but this factor is seldom taken into consideration (Leffler and White, 1997). We tested whether inclusion of parameters for environmental temperature and body mass significantly improved the fit to our DCS risk model. The assumption was that a change in either of these variables would change the blood perfusion rate, thereby affecting $\tau$. Thus, a parameter was added to the model that modified $\tau_{\text {in }}$ based on the chamber temperature $\left[T_{\mathrm{ch}}\right.$, equation (A.1)] or the animal mass $[M$, equation (A.2)].

$$
\frac{d P_{\text {tis }}}{d t}=\frac{P_{\text {blood }}}{\left(\tau+\beta_{\text {ch }} \cdot T_{\mathrm{ch}}\right)}-\frac{P_{\text {tis }}}{\left(\tau+\beta_{\mathrm{ch}} \cdot T_{\mathrm{ch}}\right)}
$$

and

$$
\frac{d P_{\text {tis }}}{d t}=\frac{P_{\text {blood }}}{\left(\tau+\beta_{M} \cdot M\right)}-\frac{P_{\text {tis }}}{\left(\tau+\beta_{M} \cdot M\right)}
$$

where $\beta$ is the corresponding parameter to be determined. For this study, neither $\beta_{\mathrm{ch}}$ nor $\beta_{M}$ significantly improved the fit to the model, as determined by the nonsignificant change in LL with inclusion of an additional parameter.

\section{REFERENCES}

Abraini, J. H., M. C. Gardette-Chauffour, E. Martinez, J. C. Rostain and C. Lemaire (1994). Psychophysiological reactions in humans during an open sea dive to $500 \mathrm{~m}$ with a hydrogen-helium-oxygen mixture. J. Appl. Physiol. 76, 1113-1118.

Ball, R., J. Himm, L. D. Homer and E. D. Thalmann (1995). Does the time course of bubble evolution explain decompression sickness risk? Undersea Hyperb. Med. 22, 263-280.

Boycott, A. E., G. C. C. Damant and J. S. Haldane (1908). The prevention of decompression-air illness. J. Hygiene Lond. 8, 342-443.

D' aoust, B. G., K. H. Smith and H. T. Swanson (1976). Decompression-induced nitrogen elimination rate in awake dogs. J. Appl. Physiol. 41, 348-355.

Dromsky, D. M., C. B. Toner, S. Survanshi, A. Fahlman, E. Parker and P. Weathersby (2000). Natural history of severe decompression sickness after rapid ascent from air saturation in a porcine model. J. Appl. Physiol. 89, 791-798.

Eichert, H and M. Fischer (1986). Combustion-related safety aspects of hydrogen in energy applications. Int. J. Hydrogen Energy 11, 117-124.

Fahlman, A. (2001). A modified Marquardt-Levenberg paramater estimation routine for Matlab. Silver Spring, MD, U.S.A.: Naval Medical Research Center, NMRC 01-02.

Fahlman, A, P. Tikuisis, J. F. Himm, P. K. Weathersby and S. R. Kayar (2001). On the likelihood of decompression sickness during $\mathrm{H}_{2}$ biochemical decompression in pigs. J. Appl. Physiol. 91, 2720-2729.

Farkas, A. (1935). Orthohydrogen, Parahydrogen, and Heavy Hydrogen, London: Cambridge University Press, pp. 167-191.

Hills, B.A. (1978). Effect of decompression per se on nitrogen elimination. J. Appl. Physiol.: Respir. Environ. Exercise Physiol. 45, 916-921.

Himm, J. F., L. D. Homer and J. A. Novotny (1994). Effect of lipid on inert gas kinetics. J. Appl. Physiol. 77, 303-312. 
Johnson, R. E. and F. L. Kiokemeister (1996). Calculus with Analytic Geometry, Boston: Allyn and Bacon, Inc.

Kayar, S. R., E. O. Aukhert, M. J. Axley, L. D. Homer and A. L. Harabin (1997). Lower decompression sickness risk in rats by intravenous injection of foreign protein. Undersea Hyperb. Med. 24, 329-335.

Kayar, S. R., M. J. Axley, L. D. Homer and A. L. Harabin (1994). Hydrogen gas is not oxidized by mammalian tissues under hyperbaric conditions. Undersea Hyperb. Med. 21, 265-275.

Kayar, S. R., A. Fahlman, W. C. Lin and W. B. Whitman (2001). Increasing activity of $\mathrm{H}_{2}$-metabolizing microbes lowers decompression sickness risk in pigs during $\mathrm{H}_{2}$ dives. J. Appl. Physiol. 91, 2713-2719.

Kayar, S. R., T. L. Miller, M. J. Wolin, E. O. Aukhert, M. J. Axley and L. A. Kiesow (1998). Decompression sickness risk in rats by microbial removal of dissolved gas. Am. J. Physiol. 275, R677-R682.

Leffler, C. T. and J. C. White (1997). Recompression treatments during the recovery of TWA Flight 800. Undersea Hyperb. Med. 24, 301-308.

Lillo, R.S. (1988). Effect of $\mathrm{N}_{2}-\mathrm{He}-\mathrm{O}_{2}$ on decompression outcome in rats after variable time-at-depth dives. J. Appl. Physiol. 64, 2042-2052.

Lillo, R. S., E. T. Flynn and L. D. Homer (1985). Decompression outcome following saturation dives with multiple inert gases in rats. J. Appl. Physiol. 59, 1503-1514.

Lillo, R. S. and M. E. MacCallum (1991). Decompression comparison of $\mathrm{N}_{2}$ and $\mathrm{O}_{2}$ in rats. Undersea Biomed. Res. 18, 317-331.

Lillo, R. S. and E. C. Parker (2000). Mixed-gas model for predicting decompression sickness in rats. J. Appl. Physiol. 89, 2107-2116.

Lillo, R. S., E. C. Parker and W. R. Porter (1997). Decompression comparison of helium and hydrogen in rats. J. Appl. Physiol. 82, 892-901.

Miller, T. L. (1989). Methanobrevibacter, in Bergey's Manual of Systematic Bacteriology, J. T. Staley (Ed.), Baltimore: William \& Wilkins, pp. 2178-2183.

Miller, T. L. (1991). Biogenic sources of methane, in Microbial Production and Consumption of Greenhouse Gases: Methane, Nitrogen Oxides, and Halomethanes, J. E. Rogers and W. B. Whitman (Eds), Washington, DC: American Society for Microbiology, pp. $175-187$.

Nishi, R. Y. (1993). Doppler and ultrasonic bubble detection, in The Physiology of Medicine and Diving, P. B. Bennett and D. H. Elliott (Eds), Philadelphia: W. B. Saunders Ltd., pp. 433-453.

Novotny, J. A., D. L. Mayers, Y. F. Parsons, S. S. Survanshi, P. K. Weathersby and L. D. Homer (1990). Xenon kinetics in muscle are not explained by a model of parallel perfusion-limited compartments. J. Appl. Physiol. 68, 876-890.

Parker, E. C., S. S. Survanshi, P. B. Massell and P. K. Weathersby (1998). Probabilistic models of the role of oxygen in human decompression sickness. J. Appl. Physiol. 84, 1096-1102.

Schmidt-Nielsen, K. (1984). Scaling: Why is Animal Size so Important? New York: Cambridge University Press.

Thalmann, E. D., E. C. Parker, S. S. Survanshi and P. K. Weathersby (1997). Improved probabilistic decompression model risk predictions using linear-exponential kinetics. Undersea Hyperb. Med. 24, 255-274.

Tikuisis, P., P. K. Weathersby and R. Y. Nishi (1991). Maximum likelihood analysis of air and $\mathrm{HeO}_{2}$ dives. Aviat. Space. Environ. Med. 62, 425-431. 
Ward, C. A., D. McCullough, D. Yee, D. Stanga and W. D. Fraser (1990). Complement activation involvement in decompression sickness of rabbits. Undersea Biomed. Res. 17, 51-66.

Weathersby, P. K., B. L. Hart, E. T. Flynn and W. F. Walker (1987). Role of oxygen in the production of human decompression sickness. J. Appl. Physiol. 63, 2380-2387.

Weathersby, P. K., L. D. Homer and E. T. Flynn (1984). On the likelihood of decompression sickness. J. Appl. Physiol. 57, 815-825.

Weathersby, P. K., S. S. Survanshi, L. D. Homer, B. L. Hart, R. Y. Nishi, E. T. Flynn and M. E. Bradley (1985). Statistically-based decompression tables I. Analysis of Standard Air Dives: 1950-1970. Bethesda, MD, U.S.A., Naval Medical Research Institute, NMRI 85-16.

Weathersby, P. K., S. S. Survanshi, L. D. Homer, E. Parker and E. D. Thalmann (1992). Predicting the time of occurrence of decompression sickness. J. Appl. Physiol. 72, 1541-1548. 